\title{
Impact Factors of Spatial Differentiation of Housing Prices in China’s Cities
}

\author{
Yang Wang, Lixia Jin ${ }^{*}$, Hong'ou Zhang, Changjian Wang, and Kangmin Wu \\ Guangdong Open Laboratory of Geospatial Information Technology and Application, \\ Guangzhou Institute of Geography, China \\ *Corresponding author: Lixia Jin, doctor, jlx906@163.com
}

\begin{abstract}
In order to explore the main driving factors of housing prices in China, we used the data of housing prices in China's 116 cities, and analyzed the impact of 3 factors including housing demand, supply and cost on housing prices based on the method of Gray Relational Degree. The results show that: The land price has the most evident driving effect on the housing price differentiations in China's cities; the driving effects from population aggregation and residential land supply are also very remarkable; the supply-demand theory and cost theory could be adopted simultaneously in explaining the housing price differentiation phenomenon in China.
\end{abstract}

Key words: house; housing prices; spatial differentiation; gray relational degree; impact factors; China

\section{Introduction}

Spatial differentiation of housing prices between cities is an important issue in the field of regional economics and urban geography ${ }^{1-3}$. In recent years, China's urban housing prices rose rapidly, and gradually reveal new patterns and new trends in terms of differentiation of housing price ${ }^{4}$. The trends are increasingly concerned by scholars. Obviously, the differentiation of housing price must be impacted by its factors. What are the main factors? There are still no generally accepted conclusions.

Resent years, the mainly conclusions are listed as follows ${ }^{5-8}$ : Urban population size and household income levels are the main factors affect the price level; Investment costs, average wages and GDP per capita impact on the price difference between Chinese 30 cities significantly; Population size, wealth level, construction costs and the security situation are the main factors of price differences; The natural environment and the quality of public service determines the price differences; The natural environment features and production environment features are influencing factors of Chinese urban housing price. Because urban sample selection, index system selection and data collection time of these studies are different, the conclusions will be various.

In fact, these impact factors can be summarized in three aspects including supply, demand and cost of house. Among them, the urban population is the key factors of housing demand ${ }^{9}$; urban residential land area can decide to house supply area; In the case of residential construction costs unchanged, residential land price determine the cost of house ${ }^{10}$, and determine the housing price. Therefore, it is necessary to analyze the China's urban driving factors of housing prices based on population agglomeration, land supply and land prices. This perspective can provide a scientific basis to regulate housing price and stabilize the real estate market. 
Thus, we explored the factors of spatial differentiation of housing price among 116 cities in China base on the data of housing prices in 2009 and 2014. In addition, we analyzed the influence of these factors for the housing prices vary among cities with different levels of housing prices. On this basis, we explored the influence mechanism of spatial differentiation of housing price. This study can provide a new empirical case to the field of urban economics and regional economics, and have academic value.

\section{Experimental}

\subsection{Data Sources}

The data of housing prices in china's 116 cities are provided by 'China Real Estate Database' of 'Qingdao Xitai Property Data Technology Co., Ltd.'. The database is composed of approximately 100 million housing units. Meanwhile, this big data can guarantee the credibility and accuracy of the urban housing price. The data acquisition time is March 2009 and March 2014. The spatial patterns of housing prices in 116 cities are shown as Fig.1.

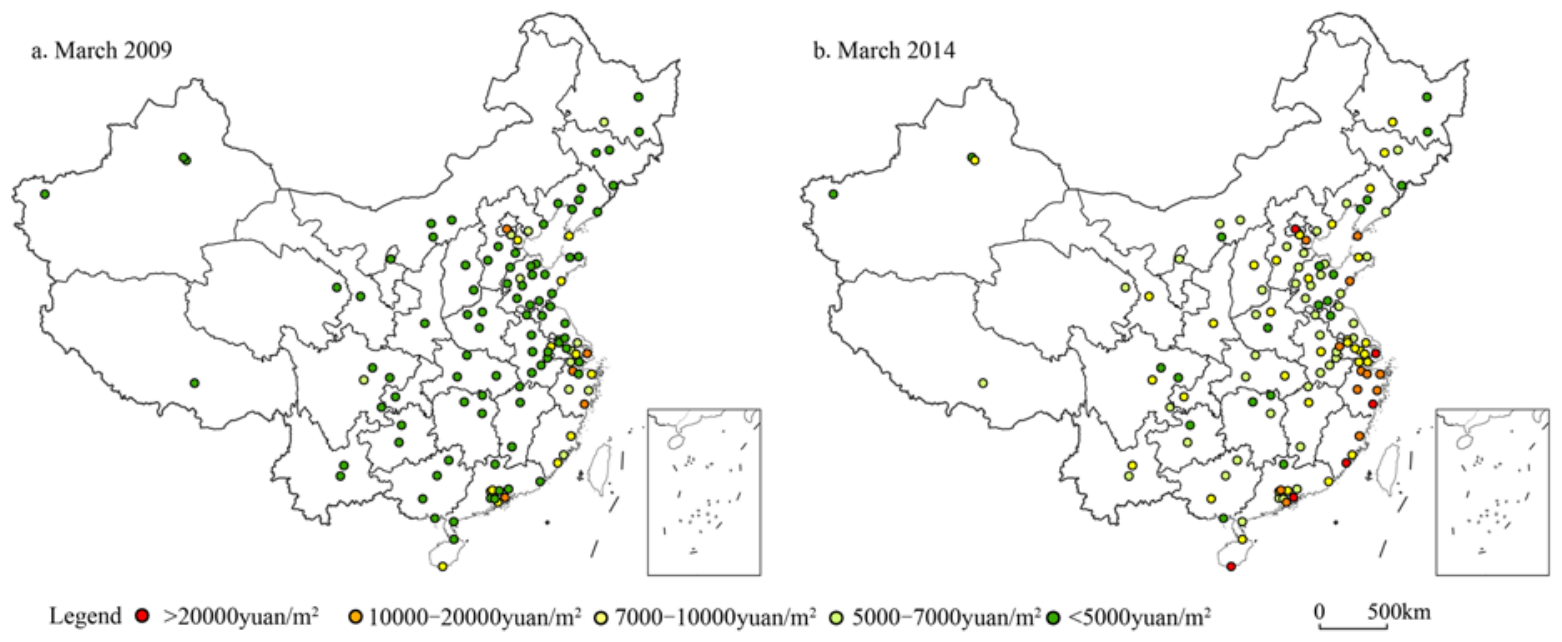

Fig. 1 - The spatial patterns of housing prices in 116 cities in China

The corresponding factors data, including urban population, residential land area, and land price, are derived from 'China Urban Construction Statistical Yearbook' and 'China Land and Resources Statistical Yearbook'. The recording time of data is 2006 and 2011. And the reasons are as follows: the time from new land supply to actual housing supply is often about 2 years. Furthermore, the time of substantive requirements and purchasing power of new urban population is usually about 2 years.

\subsection{Research method}

We judge the major driving factors of housing prices by using Gray Relational Degree (GRD). The relations between many factors in the geosystem are gray, it's difficult to distinguish the dominant factors and non-dominant factors and the relations between various factors. The gray correlation analysis provides a feasible approach for solving this kind of problems. As for the factors between 2 systems, the measurement of its relevance with changes of time or different objects is called as correlation. The correlation obtained by using gray correlation analysis is the "gray correlation". The calculation step is listed as follows ${ }^{4}$ :

The extremum method is employed for data standardization, the standardized value of the $k^{\text {th }}$ country in a certain factor sequence is: 


$$
x_{k}=\left(F_{k}-F_{\min }\right) /\left(F_{\max }-F_{\min }\right)
$$

The gray relational coefficient of the $k^{\text {th }}$ country factors $i$ and $j$ is:

$$
\xi_{i j}(k)=\frac{\min _{i} \min _{j}\left|x_{i}(k)-x_{j}(k)\right|+\rho \max _{i} \max _{j}\left|x_{i}(k)-x_{j}(k)\right|}{\left|x_{i}(k)-x_{j}(k)\right|+\rho \max _{i} \max _{j}\left|x_{i}(k)-x_{j}(k)\right|}
$$

The gray relational degree of factor $i$ and $j$ is:

$$
R_{i j}=\frac{1}{m} \sum_{k=1}^{m} \xi_{i j}(k)
$$

In the formula, $F_{k}$ is the original value of the $k^{\text {th }}$ city in a certain factor sequence; $F_{\max }$ and $F_{\min }$ are respectively the maximal value and minimal value of this sequence; $x_{k}$ is the numerical value of the $k^{\text {th }}$ city after standardization; $x_{i}(k)$ and $x_{j}(k)$ are respectively the standardized values of the factors from the $k^{\text {th }}$ country- $i$ and $j ; \xi_{i j}(k)$ is a correlation coefficient of factor $x_{j}$ and $x_{i}$ in the $k^{\text {th }}$ city; $R_{i j}$ is the gray degree of association between factor $i$ and factor $j$; $\rho$ is a resolution ratio, the general value is $0.5 ; m$ is the number of cities. In order to facilitate the quantitative analysis and to use the predecessor's research experiences for reference ${ }^{4}$, the gray relation degree is classified into 5 grades according to different intensity indices: $0 \sim 0.2$ is a very weak correlation, $0.2 \sim 0.4$ is a weak correlation, $0.4 \sim 0.6$ is a medium correlation, $0.6 \sim 0.8$ is a strong correlation, and $0.8 \sim 1.0$ is a very strong correlation. This paper defines the strong correlation as a driving factor with distinct influences on housing prices.

\section{Results and Discussion}

The newly-increased population in urban area is employed in this paper to represent the rigid demands on house, and the newly-increased urban residential land area is employed to represent the supply of new house. Because the housing price is in an inverse proportion with the supply of house, the reciprocal is taken for the residential land. Because the land price difference is a core component of cost difference, so the increment in urban average land price is used to represent the construction cost. Based on this, the growth of housing unit price is used in the paper respectively for GRD (Gray Relational Degree) with the three indicators including the newly-increased population in urban area, the reciprocal of the newly-increased urban residential land and the newly-increased land price, to explore their core influential factors.

In addition, there might be differences in the core factors to price growth in cities of different price levels. The cities with housing price below 6000 yuan $/ \mathrm{m}^{2}$ are defined as low housing price cities, the cities with housing price between 6000 and 8000 yuan $/ \mathrm{m}^{2}$ are defined as cities of medium level housing price, and the cities with housing price above $8000 \mathrm{yuan} / \mathrm{m}^{2}$ are defined as cities of high housing price. Analyze the GRD between the internal residential building prices in cities of different price levels with the various factors, and so as to explore the respective core influential factors (Table 1).

Table 1 indicates that within 116 cities in China, the GRD of the three major factors-the housing price growth and housing population aggregation, land supply and land cost is above 0.8, which indicates all these three factors have evident influences on the housing price differences in this period. Among them, the GRD of housing price growth rate and land price 
growth rate reaches 0.9779 , the leading role of land price growth is the most evident; in the demand and supply factors, the spatial differentiation of population aggregation has the highest influences on the housing price differentiation, which indicates the demand factors are more important than the supply factors.

Table 1 -The average of housing prices of 116 cites in China

\begin{tabular}{|l|c|c|c|}
\hline \multicolumn{1}{|c|}{ Scopes of cities } & $\begin{array}{c}\text { Newly-increased } \\
\text { population in urban area }\end{array}$ & $\begin{array}{c}\text { Reciprocal of newly-increased } \\
\text { urban residential land area }\end{array}$ & Land price \\
\hline All 116 cities & 0.8902 & 0.8077 & 0.9779 \\
\hline $\begin{array}{l}\text { High housing price } \\
\text { cities }\end{array}$ & 0.8512 & 0.8273 & 0.7993 \\
\hline $\begin{array}{l}\text { Medium housing } \\
\text { price cities }\end{array}$ & 0.8342 & 0.4841 & 0.9749 \\
\hline $\begin{array}{l}\text { Low housing price } \\
\text { cities }\end{array}$ & 0.9152 & 0.7998 & 0.9621 \\
\hline
\end{tabular}

The core driving factors to housing price differentiation in cities of different housing price levels are different: the land cost driving factors of high housing price cities are more weak, and its GRD with the housing price is below 0.8, the supply and demand factors have more evident influences on housing price increase, among them, the influences from demand (population aggregation) is the most remarkable; both the land cost and population aggregation in cities of medium level housing price and cities of low housing price are core influential factors to their housing price increases, while the land supply doesn't have evident influences on their housing price increases, particularly, the influences from land supply are more weak in medium-level housing price cities, and the population aggregation factors in cities of low housing prices have more evident influences on housing price increase.

Therefore, the supply-demand theory is more suitable to explain the housing price increase in cities of high housing price among the motivating factors interpreting the evident differentiation in the Chinese urban residential building prices over the recent 5 years. The fast population aggregation has posed a huge housing demand, while the housing supply speed in cities of high housing price is far from meeting the demand from population aggregation, as a result, the residential building prices in cities of high housing price are increased by very large margins; the cost theory is more suitable to interpret the housing price increase driven by land price increase in cities of low and medium-level housing price, however, meanwhile, the mismatching between residential land supply and housing increase (particularly the cities of medium-level housing price) indicates the construction land areas in some cities are expanded too fast, and the mismatching between huge housing supply and the speed of population aggregation has caused great risks to the real estate market.

According to the differentiation features reflected by urban housing prices in China over the recent 5 years, the differentiated housing regulation and guiding policy should be adopted. Continue to strictly control the newly-increased floating population in first-tier cities and some second-tier cities with too fast housing price increases, and alleviate the contending pressure on housing resources in first-tier cities caused by too fast population urbanization, meanwhile, the percentage of residential land should be increased, the housing supply quantity should be increased, so as to fundamentally alleviate the trend that the housing price is increased too fast in first-tier cities; the newly-increased residential land areas should be 
controlled in the remaining second-tier cities and third-tier cities, the speed of land urbanization should be slowed down, prevent from rash advance in land urbanization, avoid the real estate market risk and foam caused by relative surplus in housing supply. Meanwhile, encourage or attract population inflow in third-tier cities of small scale, accelerate population urbanization, and fundamentally enable the real estate market to develop more healthily and sustainably.

\section{Conclusion}

The supply-demand theory and cost theory could be adopted simultaneously in explaining the housing price differentiation phenomenon arising over the recent 5 years. The land price has the most evident driving effect on the housing price differentiations in Chinese cities over the recent 5 years; the driving effects from population aggregation and residential land supply are also very remarkable. Among them, the influences from population aggregation are more evident. This indicates the cost factor is the core in the housing price differentiation process in Chinese cities over the recent 5 years, and the demand factor is an important driving force. The housing prices in cities of different housing price levels have different driving factors, the population aggregation is the most core driving factor in driving the housing price increase in cities of high housing prices, while the driving effect of land cost is the most weak; while the land cost driving effect is the core in cities of low and medium-level housing prices, and the influence from land supply is the most weak.

\section{Acknowledgements}

This research was financially supported by the National Natural Science Foundation of China (41401164; 41571128), the Technology Plan of Guangzhou (201609020002; 201510020011), the Scientific Platform and Innovation Capability Construction Program of GDAS (2016GDASPT-0210), and the High-level Leading Talent Introduction Program of GDAS (2016GDASRC-0101).

\section{References}

1. Z. Q. Luo, C.L. Liu, D. Picken, Housing price diffusion pattern of Australia's state capital cities, International Journal of Strategic Property Management. 11(2007) 227242.

2. S. Stevenson, House price diffusion and inter-regional and cross-border house price dynamics, Journal of Property Research. 21(2004)301-320.

3. H. O. Pollakowski, T. S. Ray, Housing price diffusion patterns at different aggregation levels: An examination of housing market efficiency, Journal of Housing Research. 8(1997) 107-124.

4. Y. Wang, D. L. Wang, L. H. Liu, et al, Spatial differentiation of urban housing prices and its impacts on land market in China, China Land Science. 29 (2015) 33-40. (In Chinese)

5. J. Chen, F. Guo, Y. Wu, One decade of urban housing reform in China: urban housing price dynamics and the role of migration and urbanization, 1995-2005, Habitat International. 35(2011): 1-8. 
6. Q. Li, S. Chand, House prices and market fundamentals in urban China, Habitat International. 40(2013):148-153.

7. H. Wen, A. C. Goodman, Relationship between urban land price and housing price: Evidence from 21 provincial capitals in China, Habitat International. 40(2013):9-17.

8. Z. Wang, Q. Zhang, Fundamental factors in the housing markets of China, Journal of Housing Economics. 25(2014):53-61.

9. P. Fortura, J. Kushner, Canadian inter-city house price differentials, Real Estate Economics. 14(1986): 525-536.

10. O. Bischoff, Explaining regional variation in equilibrium real estate prices and income, Journal of Housing Economics. 21(2012): 1-15. 